\title{
La filosofía en la vida y la vida de la filosofía
}

\author{
JOSÉ LUIS L. ARANGUREN \\ Universidad Complutense
}

A lo largo del mes de marzo de 1992, el profesor Aranguren dictó en la Residencia de Estudiantes de Madrid, ante un nutrido auditorio, las cuatro conferencias cuyo extracto ofrecemos a continuación. Con ellas se inauguraban las Conferencias Aranguren que el Instituto de Filosofía del Consejo Superior de Investigaciones Cientificas proyecta organizar anualmente con el fin, según rezaba el programa de mano de esta primera edición, «de acoger en el futuro el diálogo plural entre las muchas maneras de hacer filosofía en nuestra lengua, en un momento en que se aprecian sig- nos de renovada actualidad del pensamiento filosófico hispánico y en el que éste se encuentra requerido por la urgencia de hacer frente al desafio de un mundo en crisis". Isegoría desea agradecer a José Luis L. Aranguren, que ha estado vinculado al Instituto de Filosofía desde su fundación como presidente de su Patronato, la oportunidad de dar a conocer este texto inédito, al que en su momento seguirá la publicación de las sucesivas Conferencias, cuya próxima edición correrá a cargo del prolesor Ernesto Garzón Valdés de la Universidad de Maguncia.

\section{Introducción}

Pocas veces he vuelto sobre lo escrito y cuando lo he hecho ha sido casi siempre a modo de consulta de biblioteca y casi como si leyera un libro ajeno. Ahora, por cuarta vez después de Memorias y esperanzas españolas, el esquema de autobiografía que publiqué en la revista Triunfo, y el epílogo que, bajo el título de "autocrítica ante un espejo», puse al libro Talante, juventud y moral, selección de textos míos llevada a cabo por Feliciano Blázquez, he aceptado, bajo la amable invitación de los queridos amigos del Instituto de Filosofía, la tarea de relcerme con un propósito yo diría que senil (pese a que muchas veces he declarado que «me sé viejo pero no me siento viejon): cl análisis, doble análisis, de lo que ha sido la filosofía para mí, en mi vida, y de cómo he vivido la filosofía. $\mathrm{O}$ dicho de otro modo, la presentación de mi autobiografía filosótica, de mi autobibliografía. Y para ello empezaré por relatar la situación dentro de la cual he vivido en mi juventud y he encontrado, relativamente tarde, la filosofía.

¿Primum vivere, deinde philosophari? En cierto modo sí, filosofía es re-flexión, el búho del saber levanta su vuelo tarde, si no en el crepúsculo. Pero, ¿somos plenamente aquello de lo que no somos plenamente cons- 
cientes aún? El año 1953 escribí un artículo, «Nuestra Señora del Recuerdow, con ocasión del regreso, por primera y última vez, al colegio donde me eduqué, cuando cobré plena conciencia de que mi pasado de «Prefecto, Príncipe, Emperador» había quedado clausurado allí.

Filosofía es, sin duda, re-flexionar, "volver", pero también vivir, "ir" -vivere est etiam philosophari-, ser más fieles al tiempo que cambia que a la permanencia en lo que fue. Mi vida, exteriormente tranquila, ha sido siempre inquieta, en la que todo ha ido quedándose atrás. Pero, y esta es la cuestión aquí, ¿no ha acontecido lo mismo con mi filosofía o, mejor dicho, la filosofía que, por haberla ido profesando, puedo llamar mía, aun cuando en sus fundamentos la haya aprendido de otros?

Sí, yo también soy mi circunstancia, la circunstancia ha modelado mi actitud y mi obra. De familia acomodada pero nada intelectual, descubrí la filosofía tarde. Mis inicios estudiantiles en el colegio fueron ajenos a la filosofía porque la formación escolástico-jesuítica de nuestros profesores nada tenía que ver con los textos para el examen en el Instituto donde, por ejemplo, Eloy Luis André, discípulo de Wundt, no podía sernos explicado en clase pero, por otra parte, tampoco se podía «perder el tiempo» enseñándonos «otra» filosofía, por lo cual la solución era aprender el texto prácticamente de memoria.

Fue estudiando Derecho cuando entreví el sentido de la filosofía y por ello, al terminar aquella carrera, ingresé en la Facultad de Filosofía. Pero, no un chiquillo ya sino mayor de edad, me comporté más bien como alumno libre, leyendo más que asistiendo con regularidad a clase. La Sección de Filosofía, completamente orteguiana, bajo el decanato de García Morente y con profesores tan excelentes como ellos y Zubiri y Gaos, era ejemplar, única. El orteguismo y la Biblioteca de la Revista de Occidente - Brentano, Max Scheler, Landsberg — fueron mis macstros.

Estalló la guerra civil, que vivi - por primera vez- en la soledad. Al comienzo sin nada que hacer, pronto seis meses en Toledo, donde no conocía prácticamente a nadie, y junto al frente pero de espaldas a él. La poesía de san Juan de la Cruz, de la cual me he seguido ocupando hasta ahora, y libros como Lo Santo de Rodolfo Otto fueron mis lecturas preferidas. $\mathrm{Y}$ una vez movilizado, mi servicio militar fue mínimo, con lo cual pude seguir viviendo entre los libros. Durante el período de la inmediata postguerra, hasta terminado el año 1941, en virtud de una supuesta tuberculosis, continué en la inacción, la lectura, el estudio, la meditación. Filosofaba ya, pero, como monsieur Jourdain hablaba en prosa, sin saberlo.

En 1942 entré como becario, más bien honorario, cn el Instituto de Filosofía del CSIC ¿Qué hice allí? Principalmente traducir para mí mismo El espinitu de la liturgia de Romano Guardini (al que llamaré catolicismo clasicista religioso) que empalmaba bien con la lectura, primeramente periodística, del "Glosario», luego de los libros de Eugenio d'Ors (lo que 
llamaré catolicismo clasicista, más cultural que religioso). Por otra parte traducía también Sein und Zeit de Heidegger (en ejemplar que me trajo un familiar de Alemania, correspondiente a la quinta edición, de 1941, primera en la que no aparecía ya la dedicatoria a Husserl), leía asimismo a Unamuno y a Kierkegaard y, entre los poetas, a Rilke, a la vez que continuaba con san Juan de la Cruz.

Así pues, mi vocación, mi vocación primera estaba ya claro que iba por ahí Catolicismo y Filosofía, en relación y tensión. Y mi recreación también: Poesía y Literatura.

¿Cómo encajaría - y cómo cuajaría - todo esto? Había que esperar la oportunidad. Hasta entonces mi vida intelectual había sido estetizante y filosofante, entre el ocio y la ociosidad. La posición económica familiar me lo había permitido y la supuesta enfermedad me lo había impuesto... Reconocida ya mi buena salud, consideré llegado el momento de darme a conocer, pero, al no haber mantenido vivas las relaciones universitarias, recurrí a los concursos. Se convocaron dos que me venían como anillo al dedo: el primero en 1942, con motivo del centenario de su nacimiento, sobre "San Juan de la Cruz, maestro de la vida espiritual $* . .$. que fue declarado desierto. Y el otro, sobre Eugenio d'Ors, en 1944, convocado por la Junta Patrocinadora del Misterio de Elche, en el que obtuve el primer premio y unas glosas entusiastas de don Eugenio sobre mí. Y así, de la mano de d'Ors, ingresé en la vida pública intelectual.

\section{I. ¿Catolicismo cultural, protestantismo existencial?}

A. La filosofia de Eugenio d'Ors (1945). Esta primera obra mía fue también la primera sistematización de su filosofia, algo que él no había hecho aún. ¿Por qué? Abramos un breve paréntesis sobre lo que podemos llamar la relación entre "cátedra" y "sistema». La doble (mala) suerte de d'Ors consistió en que perdió la cátedra, y el venirse a Madrid, por discrepancias con el nuevo gobierno de la Mancomunidad, fue como irse a Sevilla, es decir que perdió su silla, ocupada ya en la capital por Ortega y Gasset. De ahí que su filosofía, presentada además tarde por mí, no encontrara toda su merecida recepción ni en Cataluña, su lugar natural, ni en general, en España.

No puedo presentar aquí el resumen de su sistema. Destacaré solamente, a los efectos que ahora importan, su intento de superación de la antítesis de racionalismo e intuicionismo, mediante lo que él llamó el "pensamiento figurativo", el pensar, sí, pero también «con los ojos». A la «filosofía de cátedra» opuso la filosofía «usual», el seny y la función «irónica» de la filosofía. Y hallazgo suyo fue lo que denominó «ciencia de la cultura», es decir, el estudio de las "constantes históricas" o estilos clásico y barroco, alternantes a lo largo de ella. Estos estilos trascienden del arte e 
impregnan la cultura toda, en virtud de la interdisciplinariedad y correspondencia que se da en ella, característica bien ejemplificada en el trabajo Coupole et Monarchie.

D'Ors influyó sobre mí, aparte el punto concreto que estamos empezando a desarrollar aquí, en cuanto a su estilo de escribir, estilo «conceptista», "difícil» pero no "oscuro" en él, "sucinto" pero no «dificil», espero, en mí. Es verdad que hay wotro» d'Ors, no clasicista, el de Cuando ya esté tranquilo y la Oceanografía del tedio, no bien estudiado aún.

Durante los años de la inmediata postguerra aconteció en España una boga de lo que estoy llamando el clasicismo católico. La influencia de Romano Guardini, de la significación católico-cultural del monasterio benedictino alemán de Maria Laach y su abad Herwegen y, en suma, según d'Ors, el primado del logos sobre el ethos (en contraste con el Heidegger de Sein und Zeit, que sustentaba el primado del ethos e incluso de la Befindlichkeit) son visibles en la revista más importante de la época, Escorial, donde tenía una sección fija Genadio Sanmiguel, O.S.B. Revista Escorial a cuyo título se opuso, por cierto, cuando fue propuesto, Rafael Sánchez Mazas, por considerarlo, más que clásico, barroco.

B. Catolicismo y protestantismo como formas de existencia (1952). Es un libro en el que empecé a pensar desde 1944, a partir de las categorías orsianas de lo clásico y lo barroco que, a los efectos de análisis religioso que a mí me importaban, tendí a sustituir por las de lo católico y lo protestante. Pero había que ahondar en el supuesto antropológico, es decir, en el «tono vital», en lo que denominé — creo que por primera vez - "talante», en el modo radical y permanente de "ser» o "estar» en el que cada cual "se encuentra" (Befindlichkeit). Importaban a los efectos de mi investigación dos clases extremas de talante: el otium y studium como manifestaciones de un temple fácil y seguro, según los consideró Heidegger, y el talante que, comenzando por el "cuidado" o preocupación, desemboca en angustia y desesperación.

En relación con el talante se ha de poner la situación, situación histórica que condiciona el talante colectivo: y así puede distinguirse un modo de ser "católico» y otro "protestante», no sólo en los que siguen siéndolo religiosamente - un Romano Guardini, un Henri Brémond y su Divertissement devant l'Arche, un Eugenio d'Ors, por un lado, y por otro un san Agustín, el occamismo entero y Lutero- sino en quienes han dejado de ser religiosos e incluso pueden oponerse a la religiosidad; así, un Stefan George e incluso un Voltaire, de una parte, un Rousseau, un André Gide o los representantes de la filosofía de la existencia, por la otra.

El acercamiento al título del libro durante el período de gestación, 1944-1952, fue laborioso. "Cristianismo: Catolicismo y Protestantismo (Un estudio sobre el sentido católico y el sentido protestante de la vida)» fue el primero que se me ocurtió. D'Ors, muy en su estilo, me propuso «El 
genio del Catolicismo». A continuación se me ocurrieron "El hombre y el estilo del Catolicismo", más tarde "Catolicismo y protestantismo como modos de ser» y finalmente el que prevaleció, «Catolicismo y protestantismo como formas de existencia».

El punto de partida de la investigación fue, según se infiere de lo dicho, la hipótesis ideal de adscribir cada forma de religión a uno u otro talante. El punto de llegada o tesis final y síntesis del libro fue la de que cabe un catolicismo existencial del que son testimonios vivos, en la Antiguiedad, san Agustín, en la Modernidad, Mauriac, Graham Greene, Simone Weil. La Gracia puede descender sobre cualquier Naturaleza o Talante.

C. El Protestantismo y la moral (1954). Este libro se sitúa en el tránsito de la primera etapa, religiosa o de filosofía de la religión, a la segunda, ética, de mi obra. El 20 de abril de 1953 me propuso Pedro Laín, rector de la Universidad de Madrid, estando ambos siguiendo el curso de Zubiri sobre "El problema del hombre", que me preparase para concursar a la cátedra de Ética y Sociología de dicha Universidad, que había de ser sacada a oposiciones, pues estaba vacante desde la muerte de García Morente. Esta cátedra había sido el resultado de la fusión de otras dos, la de Ética de García Morente y la de Sociología (en realidad de :Doctrina social de la Iglesia», expresión de la voluntad eclesiástica de presencia en la Facultad) de don Severino Aznar.

El libro, pues, debería significar el giro de mi obra a la filosofía moral, e incluso socio-moral, en el estudio del protestantismo. Su estructura sería semejante a la de Catolicismo y protestantismo pero con aplicación ahora del concepto de actitud (Haltung heideggeriana), introducido ya en mi anterior obra, entendido como talante penetrado de logos y, sobre todo, de ethos, es decir, como formalización intelectual y moral del talante. Las posiciones enfrentadas fueron, pues, el luteranismo como talante religioso y el calvinismo como actitud jurídico-religiosa. $\mathrm{O}$, dicho de otro modo: religión como gracia (fe) y religión como justicia. En efecto, desde los romanos y aún antes, la religión fue entendida como cumplimiento de los deberes para con Dios, o los dioses, de tal modo que el hombre religioso era el religens o cumplidor, frente al negligens o descuidado de ellos. Luego, en la Edad Media se distingue, de esta virtud religioso-moral de religens u hombre religioso, el estado religioso o de entrada en orden religiosa. (El profundo concepto zubiriano de religio como religatio brilla por su ausencia). Y más tarde el occamismo y Gabriel Biel, que tanto influyó sobre Lutero, fueron, a la vez; y un tanto contradictoriamente, semipelagianos (el hombre puede, por sí, cumplir los Mandamientos) y sustentadores de la "potencia absoluta" de Dios, que puede, por sí, salvar o condenar. Es decir, mantenedores, simultáneamente, del juridicismo (humano) y la (divina) Arbitrariedad.

Lutero vino a rechazar tajantemente el juridicismo: el hombre no pue- 
de nunca, de ninguna manera, ser justo para con Dios. Su intento -moral religiosa - es vano y suscita un talante de tristitia, insecuritas y finalmente angustia y desesperación. Los Mandamientos son imposibles de guardar, pero aun cuando - per impossibile - lo fueran, la salvación no puede venir de su cumplimiento. El punto de vista jurídico-forense de la imputatio y la reputatio es rechazado como recaída de la religión en contabilidad religiosa. (Contabilidad religiosa de la que, a su modo, hará posteriomente uso Ignacio de Loyola en su doctrina del examen de conciencia). La religión es para Lutero pura y sola fe: pecca fortiter.. sed crede fortius. El calvinismo recae en la contradicción occamista: por una parte su dogma central es el de la Predestinación, mas por la otra afirma la actitud ética del religens, del justo para con Dios, contradicción de la que pretende salir en tanto que esa justicia para con Dios es reivindicada como obra de Dios (predestinación y elección divina) en nosotros: somos buenos por elegidos y no a la inversa. A los predestinados puede reconocérselos por el "signo" de la laboriosidad, el ascetismo intramundano, la justicia como virtud, la honradez y los frutos de estas virtudes. Posteriormente, el calvinismo puritano, una vez secularizado, ha desarrollado en los Estados Unidos, a su modo, la doctrina del "pueblo elegido", bajo la fórmula del "Destino Manifiesto". Pero esta última reflexión pertenece a una etapa ulterior de mi obra.

Si me es permitido acogerme, por un momento, a la fórmula kierkegaardiana de los tres estadios, en mi obra sucesivos y meramente reflexionados, yo diría que aquí termina mi estadio "religioso". A continuación trataré del estadio "ético" y, para terminar, del estadio "Sociopolítico".

\section{Etica}

Con la preparación y obtención de la cátedra de Ética, comienzo el segundo estadio en el camino de mi obra, del que voy a hablar en este capítulo. Mi libro Ética, resultado de la Memoria de Cátedra, es, otra vez, una síntesis. En el Prólogo hablo de «eslabones»: Aristóteles, santo Tomás y Zubiri. Pero detrás del nombre de Zubiri quedaban los de Ortega y, tal vez sobre todos, Heidegger.

Sí, pienso que, en su primera parte, es un libro de ética existencial, de moral pensada y, a la vez, vivida. La atención que, en lo referente a esto segundo, se presta a los Moralistas se corresponde con la dedicada a los puritanos o calvinistas del libro inmediatamente anterior, El protestantismo y la moral. Libro, el que releemos ahora, que, sin embargo, deja el "apasionante tema de la ética social y política para otra ocasión», que aquí será la de los capítulos siguientes.

La Primera Parte, sin duda la más original, trata de los principios, del punto de partida, del método (en el sentido literal de la palabra "principio»: el filósofo como uprincipianten, que piensa los problemas desde su 
principio). Pero no con un conjunto de reglas de las que se dispondría de antemano, sino con la vía o camino circular -anticipación y repetición-. el círculo metodológico no vicioso, cuyas reglas irian desprendiéndose por sí mismas en el curso de la investigación.

1) El primer principio es el etimológico (relación de filosofía y filología, tan cara a Heidegger) y mis orientadores aquí fueron él y Zubiri. La diferencia, en el presente contexto, entre êthos-hábitos y êthos-carácter (modo de ser) viene a constituirse en paralelo a aquella otra, que ya conocemos, entre talante y actitud. La actitud, veíamos, procede del talante, un talante afirmado y constituido, de alguna manera como el carácter procede de la reiteración y afirmación de actos, convertidos en habituales, y configurando un modo de ser. En uno y otro caso se trata, como decía Zubiri, de una "apropiación" del modo de ser.

2) El segundo principio o principio prefitosófico es la percepción de que el hombre, antes de hacer filosofía y filosofía moral, es ya moral, en tanto que tiene que hacer su vida - «conducta» procede de «conducirse»-, tarea que, en contraste con el animal, cuya vida le es dada ya hecha por la conexión estímulos-respuestas, es vida como «quehacer». Quehacer que él inventa 0 , las más de las veces, que él «sigue», "prosigue»; pero que es suyo, ya que, aun cuando se comporte "como» los demás (moral establecida), tiene que tomar la decisión de hacerlo así.

3) El principio psicológico o antropológico, en estrecha conexión con el anterior, es muy importante, porque importa, por una parte, evitar el psicologismo moral, entonces, cuando escribí el libro, todavía en boga; y, a la vez, porque importa reconocer la realidad constitutivamente moral del hombre, lo que Zubiri denominó - por entonces sólo en un Curso hablado y no todavía por escrito- la moral como estructura.

El hombre tiene que hacer - bien o mal, esta es segunda cuestiónsu vida, vida como quehacer, vida como voluntad. Hay - esto lo vio Ortega- expresiones como "moral elevada", «desmoralización», hay la pregunta orteguiana «¿Cómo estás de moral?», que apuntan precisamente a esta dimensión previa de la moral, "protomorals, como la ha llamado otro discípulo de Zubiri, Diego Gracia. Como digo, necesariamente previa a la moral como contenido, a lo que usualmente se entiende por "moralidad" e "inmoralidad", al proceder moralmente bien o mal.

Bajo el título de Psicología de la moralidad me ocupo a continuación de la historia de la moral concreta o ethica utens, vivida, la tarea de los reformadores morales, casuistas y moralistas, ilustrados, autores de la novela psicológica del siglo XIX, existencialistas de la mauvaise foi y de la ética de la situación.

4) El principio metafísico trata de la inserción, del modo de inserción de la ética en la metafísica: bien como su punto de partida o como su 
justificación of fundamentación última; bien como su independencia, mayor o menor, de la metafísica: los valores en sí (ética de los valores, Max Scheler) o como "valoración» pura y simple; bien como sentido ético de toda filosofía; bien, en fin, en el Heidegger de Sein und Zeit, como disolución de la sustancia ética en la filosofía.

5) La Primera Parte termina con media docena de capítulos referidos a la relación de la ética o, mejor dicho, de la moral (moral vivida) con la religion. Las posiciones fundamentales son: negación, por Lutero, de la relevancia salvífica de la moral; reducción calvinista de la religión a justicia (ético-juridica) para con Dios; vuelta al revés de la cuestión y demanda de una justificación de Dios ante el hombre; y, en fin, postura del autor, apertura de la ética a la religión.

La Segunda Parte presenta una estructura más tradicional, sobre todo en tanto que terminología. Se analiza primeramente en ella el objeto material de la ética, que son ciertamente los actos y los hábitos (virtudes y vicios, sin especificar aún), pero sobre todo el êthos o carácter. Pero este objeto real, sí, ¿cómo aprehenderlo, siendo como es pura distensión temporal? Según Kierkegaard a través de esos actos privilegiados que son el «instante" y la "repetición", por los cuales se lleva a cabo la asunción existencial de la totalidad de la vida en su scntido. Y según Zubiri la asunción se realiza en el "siempre» o «de una vez por todas", en tanto que acto definitorio, y en «la hora de la muerte» en tanto que acto definitivo. Cabe e incluso es conveniente poner estos términos kierkegaardianos y zubirianos en relación con los clásicos, el griego kairós o momento oportuno y justo, y el bíblico pléroma o plenitud.

El objeto formal o especificación moral, buena o mala, del objeto material es estudiado a continuación: ¿cómo ocurre el conocimiento de esta especificación? ¿Por la ley natural? ¿Por directa revelación religiosa? ¿Por descubrimiento histórico-filosófico? O bien la ética filosófica no puede ser sino reduplicativamente formal, según el formalismo kantiano, el existencial (con sus precursores Kierkegaard y Nietzsche), o el meramente lógico, puro análisis de lenguaje moral.

Frente al serio formalismo al que se acaba de aludir cabe un formalismo moral light, usual más que filosófico, que corresponde a una experiencia de instalación y habituación en la contingencia, es decir, en la nueva experiencia de que también se puede vivir sin fundamento, en un estado de ánimo que renuncia al Absoluto. Es lo que bastantes años más tarde de escrito este libro se ha denominado Postmodernidad.

El libro se acerca a su terminación con una teoría de los sentimientos y otra de las virtudes en la línea tradicional y sendas reflexiones sobre la felicidad como placer, virtud, contemplación y perfección. (Sólo más tarde en la evolución de mi obra distinguiré entre la felicidad, que se puede 
«tocar» en algunos instantes, pero en la que es imposible vivir, y la felicidad contenida o "contento", "Estar contento", "vivir contento" es el sucedáneo humano, realista, del ser feliz.)

$\mathrm{Y}$ el libro se cierra con una reflexión sobre la muerte: muerte aceptada, muerte negada (simple pasaje a otra vida), muerte apropiada (Rilke, Heidegger), muerte buscada (impulso tanático), muerte absurda (neantización de toda posibilidad).

Por los mismos años de la Ética o un poco antes (1956), publiqué como trabajo de cátedra el librito Cuatro actitudes del hombre ante su bien, que tomó como punto de partida la Primera Carta de Séneca a Lucilio. Se dice alli:

\section{Maxima pars vitae elabitur male agentibus, Magna pars vitae elabitur nihil agentibus. \\ Tota vita elabitur aliud agentibus.}

La primera actitud es la aversión al bien; la segunda, la indiferencia; la tercera, la diversión. Pero cabe también el bene agentibus, en tanto que conversión en el decurso de la vida. $Y$ también, según Nietzsche, la «repetición", a lo largo de su decurso. "Mantenella y no enmendalla" y "arrepentirse" son los dos modos extremos de ir recorriendo el camino de la vida.

La ética de Ortega (1958). Continúo en la tarea de la ethica docens, es decir, en el esfuerzo de entendimiento y, si posible fuera, de síntesis de la autodenominada "filosofía perenne» con la ética contemporánea.

El trabajo se escribió con el propósito concreto de hacer inteligible a Ortega desde la Escolástica y salir así al paso de los ataques de entonces (P. Ramírez), sin duda con la intención de que las obras de Ortega fueran incluidas en el Índice de Libros Prohibidos, como ya se había hecho con las de Unamuno.

En parte, pues, esta obra debería tratarse también en la sección final de esta autobiografía o autobibliografía, esto es, desde la perspectiva de un intelectual católico que, en el ejercicio de su oficio crítico, critica al poder eclesiástico, de modo análogo a como habrá de criticar después al poder politico.

Pero aquí se critica también al propio Ortega: habiendo sido él quien se adelantó al concepto zubiriano de la "moral como estructura", tiende a encabalgar los dos planos de la estructura y el contenido uno en el otro, ensanchando el primero, genus moris o moralitas in genere, a expensas de la especificad moral de lo honestum/inhonestum o bueno/malo. «Llega a ser el que eres» es la regla moral orteguiana. Lo importante es la magnanimidad, la grandeza de ánimo capaz de alcanzar esa meta, en el límite, para bien o para mal. 
Un segundo punto importante en la ética orteguiana es su anticipación del concepto zubiriano del êthos como objeto material de la ética. En cuanto al objeto formal de la ética como "perfección" o "misión", posee, sí, una norma objetiva, los valores de Scheler, a quien sigue en este punto, pero quizás no advierte suficientemente que éstos no vienen dados, sino que se configuran a lo largo de la vida en situación. Hay en Ortega una exageración del imperativo "Llega a ser el que eres». No es la suya una ética en situación, sino pura ética de la magnanimidad enteramente genérica.

En fin, Ortega predica una ética de la felicidad a la que se tiende necesariamente, pero que no se logra, es utópica. ¿Significa esto una posible "apertura de la ética a la religión»?

La enseñanza de la Ética (1954). Quiero aprovechar la existencia de esta publicación para hablar no tanto de ella como de mi modo de enseñar la ética cuando, a partir de fines del año 1955, empecé a profesar mi asignatura. Desde el principio orienté mis clases en el extremo opuesto al de las lecciones magistrales, es decir, como auténticos seminarios, con participación oral y abundante de los alumnos, hasta el punto de que, al final del curso, los conocía a todos - que eran pocos- tan bien que no eran menester exámenes o, a lo sumo, con algunos llevaba a cabo un examen oral-conversación, siempre sobre el tema elegido por el alumno. Tan importantes como los cursos eran los seminarios propiamente dichos. Aparte de los eminentes profesores extranjeros y españoles que, gracias al apoyo económico de instituciones francesas, podía traer como invitados, los míos personales siempre constituían un lazo de unión de la filosofía con la literatura. Así, dediqué un seminario a la confrontación de la Antígona de Sófocles con la de Anouihl, otro a los moralistas franceses, sendos seminarios a Quevedo y a Baltasar Gracián, al Quijote y Cervantes, a san Juan de la Cruz, a Los justos de Albert Camus, a la novela moderna... La poesía en especial y la literatura en general pienso que con frecuencia constituyen una prefiguración de la realidad luego conceptualmente filosófica. De ahí algunas de mis obras, así, "Poesía y existencia" y otros trabajos recogidos en el libro Critica y meditación (1957) y Estudios literarios (1976), donde aparecen algunos de los seminarios aniba citados. Mis artículos sobre Rilke y mi "descubrimiento" para españoles de la Península de la obra de María Zambrano, que funde filosofía y poesía, también deben ser citados aquí.

Roland Barthes distinguió del auténtico écrivain o escritor, a quien importa, y mucho, el cómo escribir, el écrivant (neologismo inventado por él), solamente concernido con lo que escribe. Yo habría querido ser lo uno y lo otro.

Lo que ocurre es que el modo de mirar a las cosas, la distancia con respecto de ellas, la adaptación de la retina espiritual han de ser, creo yo, 
bastante diferentes en quien piensa sobre las cosas y en el que las describe al mismo tiempo que las vive. Compaginar el escribir pensando con el vivir escribiendo es un ideal que no he logrado alcanzar.

\section{Etica y moral}

La característica general de esta nueva etapa de dedicación a la ética consistió en una liberación del corsé académico y en cierta medida escolástico, imprescindible en unas oposiciones, sobrc todo de aquella época (1955). Afianzado ya en mi cátedra y consciente del gran interés con el que los alumnos seguían mis clases, completamente diferentes de las dcmás, comprendí que ya no podia tratarse de construir o reconstruir un sistema de ética (que, bueno o malo, ya lo había hecho) sino de tratar de problemas morales en una enseñanza viva.

Hay en este periodo un trabajo, Marxismo como moral (1968), que a primera vista se diría emparentado con La ética de Ortega (1958), en cuanto que los dos respectivamente se proponen "salvar» una y otra filosofía desde el punto de vista ético. Pero el método es completamente distinto. Allí se trataba de disputar con la Escolástica y por tanto tenía que hablar un lenguaje comprensible para ella, en definitiva el de mi Etica. Ahora de lo que se trata es de participar, como en otras ocasiones hice, en los diálogos cristiano-marxistas, entonces en boga, y de mostrar, tanto al cristiano como al marxista economicista, que el marxismo posee una moral propia, si bien es verdad que la palabra "moral» aparecía, en la época de Marx, como bastante desacreditada.

Cuando este trabajo se escribió, del marxismo se había pasado a los marxismos, incluso a algunos tan sui generis como el estructuralista de Althusser, y como punto metodológico de partida apliqué al caso la filosofía analítica, el análisis lógico del lenguaje. Éste posee dos dimensiones, la meramente emotiva y la cognitiva. Desde el punto de vista tradicional, la emotividad negativa, lo diabólico, el Diablo, han tenido para el católico convencional sucesivas encarnaciones históricas: Lutero, Voltaire, Marx y consiguientemente el sistema todo de este último, el marxismo, para colmo, según moda de entonces, materialista.

Pero si, por el contrario, atendemos a la dimensión cognitiva, hay que distinguir en la Economía moderna dos direcciones fundamentales: la psicológica (que parte del egoísmo racional) de Adam Smith, y la sociológica de Marx que, partiendo del sentimiento social de solidaridad, se propone no sólo la interpretación del mundo sino la tarea de cambiarlo, liberando de su explotación al proletariado. Tarea, pues, eminentemente moral. Es verdad que, según Marx, el proceso histórico de desarrollo del materialismo liberador obedecía a un ley histórica inexorable, pero aun así cabía la intervención de la moral para acelerar el proceso, dotar al 
proletariado de conciencia de clase y de voluntad de lucha de clases, crear el partido comunista (Lenin) como vanguardia de un proletariado más bien inclinado de por sí al "reformismo", pero que el partido debía arrastrar a la revolución. Tarea, como se ve, lo reconociera así Marx o no, moral.

En esta misma línea de inseparabilidad de teoría y praxis, de comunicación para la acción, cabe situar mi libro La comunicación humana (1965), el más difundido de los míos, publicado en nueve o diez idiomas. Esta obra quiso presentar una teoría general de la comunicación, pero lo que importa subrayar aquí es su énfasis en la prospectiva comunicacional, en la comunicación como actividad o lenguaje-para-la-acción; o, dicho de otro modo, consistente en una pragmática del lenguaje, de todos los lenguajes.

Este estudio, como "neutral» desde el punto de vista valorativo que es, apunta mucho más directamente a la moral como estructura, a la vida como «quehacer», cualquiera que éste sea, al genus moris en general, que a su especificidad moral como comportamiento bueno o malo.

En Moralidades de hoy y de mañana (1973) se empalma con el trabajo anterior pero centrándolo ya en la moral, y se estudian la "comunicación pragmática», la «previsión tecnocrática» y la "futurología» al servicio del Derecho del Porvenir, del «Derecho Natural» de Ernst Bloch, de la prospectiva moral y de la moral utópico-contestataria.

Moral y sociedad (1966) es, en realidad, una historia de la moralidad española, de los mores colectivos o formas sociales de vida a lo largo del siglo XIX, desde sus vísperas, la moral de la Ilustración (Jovellanos), de pedagogía moral y de libertad pero limitada por el Despotismo Ilustrado, hasta el estudio de las estructuras socialmente concretas en una época en la que se adquiere (por Galdós y sus Episodios nacionales) una visión plástica de la Historia: romanticismo político (Constitución de 1812), romanticismo anterior y mucho más auténtico como forma de vida que como literatura, forma "moderada" de existencia, moralismo de la izquierda, ethos de la Restauración (oligarquía, bipartidismo, caciquismo y clericalismo) y, en fin, ethos pedagógico de la Institución Libre de Enseñanza.

"El ocio y la diversión en la Ciudad" (1958) es un estudio que contrasta el ocio antiguo, contemplativo, studium o skholé, estudio como afición, y asimismo el descanso, juego y fiesta (paidiá y paideia), con el sentido de la virtud primordial del trabajo (nec-otium) y la diversión, alienación y hobby (originariamente, "chifladura»).

Lo que sabemos de moral (1967) fue el título primero de esta obra, impuesto por el general de la colección donde se publicó («Lo que sabemos de...,) y que en edición ulterior cambié por el de Propuestas morales.

Lo que primero choca en este librito, comparado con la Ética, es el cambio de lenguaje e intención -los giros lingüísticos y la pretensión mis- 
ma de entendimiento con la Escolástica han desaparecido-y, enseguida, es nuevo también el «aparato críticon de citas y apoyo en otros pensadores. Los clásicos han desaparecido, Zubiri y Heidegger también, Ortega casi del todo y ahora son los angloamericanos los que se citan. (Y, por ejemplo, con referencia a lo que antes llamaba «objeto material» de la Ética, ya no se habla del ethos sino del way of life o del "patrón del comportamiento: tiene razón Margarita Rivière, a todo llega el "poder de la modas, hasta a la filosofía.)

Pero no sólo el tono, también la estructura y función han cambiado. La Ética estaba destinada al estudio por los alumnos de la asignatura (aunque yo nunca asigné «libro de texto» alguno, ni repetía nunca en clase lo que el libro decia). Por el contrario, este libro no es para ser estudiado. Pretendía ser, más bien, una presentación de la problemática de la Ética en sus primeros capítulos y de moral en los siguientes. Y de propuestas, sí, pero no tanto de un contenido como de la actitud que se ha de tomar ante la vida y que en realidad es enseñada por la vida misma.

Prescindiendo de supuestos metafísicos, el análisis, influido por los filósofos ingleses Toulmin, Nowell-Smith, Hare, etc., consistió en el de los términos «bueno», "felicidad", "utilitarismo de la sociedad del bienestar", de la "empresa de la moralización», de la «decisión por razonamiento y no por persuasión» y de los «caracteres de la crisis actual de la moral».

Pero en este libro, lo más actual para mí, pues el enfoque analítico quedó ya atrás, es el Anexo en que trato de los "Nuevos enfoques de la moralidad»: el estudio de la estrecha conexión entre la macromoral y la minima moralia, la relación entre la autonarración y la autointerpretación, la correlación entre la ética en filosofía y la pragmática en lingüística y finalmente la interdisciplinariedad como apertura ética a toda suerte de saberes disciplinados e indisciplinados para la captación de la auténtica moral vivida, me siguen apareciendo como temas fundamentales.

Ética narrativa. Es un tema este de la ética narrativa que yo considero central en mi pensamiento y al que, sin embargo, no he dedicado nunca sino artículos aislados, conferencias y alusiones. $Y$ no más, sino menos, es lo que puedo hacer a continuación.

El hombre, cada hombre, es "individuon, y con esta palabra estoy rememorando el individualismo ético de mi querido amigo Javier Muguerza. Pero cada individuo es asimismo «di-viduo", es decir, alter ego. Como vio George Herbert Mead y ha recordado Habermas, la mismidad surge en relación con la alteridad, con el otro del que me percibo y encuentro diferente y, a la vez, cobro conciencia de la entidad del otro, de la mía y de la interiorización de "otro", del alter ego en mí. Y esta dualidad interior da lugar a que surja el diálogo intrasubjetivo que cada cual mantiene consigo mismo, diálogo que cuando se produce al compás de lo que se va haciendo denomino "narración narrante» y es como el «diario» que, escrito o no, 
llevamos cada día, en conversación con nosotros mismos, de lo que vamos haciendo, como si fuéramos hablando con otro. Narración y hasta teatro para sí mismo, en el que cada cual es actor, autor y hasta, imaginariamente por lo menos, director de escena. Pero esta autonarración puede no ser proyectiva, no marchar al paso de los acontecimientos o adelantándose un tanto a ellos, sino que, por el contrario, puede producirse a posteriori, no como "diario", sino como "memorias", en cuyo caso hay que hablar no de "narración narrante» sino de "narración narrada», Es en definitiva lo que, no como narración de mi vida, pero sí como narración de mi obra, estoy haciendo aquí.

A través de la autonarración con sentido afirmamos el sentido de nuestra vida. A sensu contrario, una narración como L'étranger de Albert Camus, totalmente sincopada, rota, mostraría el sin-sentido, el absurdo de la existencia.

Moral de la vida cotidiana, personal y religiosa (1987). Es partiendo de la actual sociología norteamericana, con la que me familiaricé durante mi estancia profesoral en California, y concretamente la sociología de la vida cotidiana, la sociología "dramatúrgica» de Goffman, la etnometodología de Garfinkel y la Escuela de Palo Alto, como llegué al planteamiento de este libro. La conocida expresión minima moralia es adecuada para su referencia a la cotidianidad. En ella, dentro de un frame o marco minisocial, adoptamos o se nos atribuye un papel que procuramos aparentar, es decir, representar.

Ese minipapel sociomoral es captado, más fácilmente desde fuera, por quienes asisten a su representación. Pero el propio actor puede lograrlo "ver" también, mediante la autonarración de que hemos hablado, siempre que ésta sea suficientemente autocrítica.

La salida de la "vida cotidiana» puede hacerse "por elevación" a lo que suele entenderse por vida pública, pero también por ahondamiento, y entonces se entra en la vida personal, que no debe confundirse con la privacy o vida "privada", que no por casualidad se llama -privada-de- así.

La vivencia del tiempo no como, en un extremo, "perderlo" o "matarlo» ni tampoco, por el otro extremo, considerándolo como si fuese «oro», es errónea. El tiempo es justamente eso, tiempo. Y la vida es tiempo.

Pero la felicidad, que es aspiración de toda vida, ¿se da en el tiempo? Se da en el instante y se da en la imaginaria lejanía, arcadia, del pasado, utopía del porvenir. Lo que de verdad se da en la vida no es la felicidad sino el contento, es decir, la satis-facción, una satisfacción no rebosante sino, como la palabra misma "contento" dice, "contenida». Y la vida vivida es la del presente pero también la del pasado en la memoria y la del futuro en la esperanza.

La radicalidad moral de una vida verdaderamente personal habría de desembocar en una moral como actitud, más allá de la moral como estruc- 
tura y de la moral como contenido. De ella he hablado en Etica de la felicidad y otros lenguajes y antes, en la "moral social", mi contribución al volumen colectivo Nuestra sociedad. Introducción a la Sociologia. Consiste en tres momentos: ruptura de la moral establecida, invención de la moral por establecer y establecimiento o remoralización en esa nueva moral.

\section{El oficio del intelectual}

El vocablo «intelectual" es, como se sabe, un neologismo inventado en francés con ocasión del Affaire Dreyfus. Vocablo y concepto que tuvo sus antecedentes en los "moralistas" de los siglos XVI y XVI, ocupados en la crítica de los usos, costumbres, virtudes supuestas y vicios que aparentaban no serlo, y en los «ilustrados» del siglo Xvw, que criticaban ya al Poder, pero con las limitaciones impuestas por el Despotismo Ilustrado. Importa recordar que antes de la creación del neologismo "intelectual», en francés se disponía ya del vocablo clerc (recuérdese el título, en su día famoso, de La trahison des clercs), que constituyó, en el siglo XIX, una secularización de la palabra "clérigo» pucs, en efecto, nuestra función es parecida a la de los predicadores, predicadores secularizados. La palabra puedc entenderse en sentido estrictamente sociológico y se refiere entonces a los creadores y distribuidores de cultura. Tomada, como aquí se hace, en su acepción ampliamente moral, deben distinguirse los intelectuales orgánicos, legitimadores del Poder (oficio que yo no he ejercido nunca), de los intelectuales críticos, que son los que aquí importan.

$¿$ Qué oficios intelectuales críticos he desempeñado yo a lo largo de mi vida? En primer lugar cronológico, el de intelectual católico, es decir, crítico del poder eclesiástico. A esta actividad corresponden mis libros Catolicismo día tras día (1955) y su auto-réplica Contralectura del Catolicismo (1978), La crisis del Catolicismo (1969), El cristianismo de Dostoievski (1970), Sobre (imagen, identidad y) heterodoxia (1982) y Moral de la vida (cotidiana, personal y) religiosa (1987).

Constituyen crítica del poder político los libros Ética y Politica (1963), La democracia establecida (1976), España: Una meditación politica (1983), y "El intelectual y el político", artículo incluido en la ya citada obra Ética de la felicidad $y$ otros lenguajes.

$Y$ aun cuando no voy a tratar aquí de ellas, permítaseme que cite las obras correspondientes a otros tres tipos de crítica que también he ejercitado. A la crítica de la cultura establecida se refieren La cultura española y la cultura establecida (1975), Misión de la Universidad (1973) y Erotismo y liberación de la mujer (1972). De crítica sociocultural tratan el artículo "La evolución espiritual de los intelectuales españoles en la emigración" (1953) y La juventud europea ( $y$ otros ensayos). Y, en fin, son obras de autocritica o autobiografia crítica el libro Critica y meditación (1957) (en donde la refe- 
rencia personal es transpuesta, en mayor o menor medida, al orden literario), la Introducción a Obras (1965), el librito Remanso de Navidad y Examen de Fin de Año (1965), Memorias y esperanzas españolas (1969), la autobiografía presentada en el número de noviembre de 1981 de la revista Triunfo y Sobre imagen, identidad y heterodoxia (1982). Pero repito que, en lo que sigue, solamente voy a resumir mis críticas al poder eclesiástico y al poder político.

1. Crítica del poder eclesiástico. Tras lo dicho al principio sobre mi formación católica primera y la dedicación subsiguiente a la confrontación del Catolicismo y el Protestantismo se comprende bien que mi primer oficio de intelectual fuera el de la autocrítica católica. La fundación por Pío XI de la Acción Católica tuvo no inmediatos pero sí importantes resultados, así sus ramas HOAC y JOC, muy relevantes frente al franquismo; y también la organización de las Conversaciones Católicas Intemacionales (1950 y ss.), de San Sebastián, primer contacto directo de los católicos españoles con los teólogos extranjeros, principalmente franceses, precursores de la teología del Concilio Vaticano $\Pi$. Asimismo las Conversaciones Católicas de Gredos (1951 y ss.) en las que, hasta mi decepción final, tuve una participación muy señalada.

Mi personal «acción católica» fue en favor de la que denominé «iglesia eclesial" y de crítica a la Iglesia eclesiástica. Este fue el sentido general del libro Catolicismo dia tras día, laical y no clerical, que fue censurado con un Monitum del Vaticano y que, lejos de suavizar, radicalicé veinte años después en Contralectura del Calolicismo.

La crisis del Catolicismo es obra en la que el compromiso personal es sustituido por la descripción objetiva de las consecuencias de la creciente secularización. Al catolicismo conciliar y postconciliar de los años sesenta se ha respondido, por la derecha, con el catolicismo de la Restauración. Por la izquierda han surgido católicos disidentes con escasa o nula identificación eclesiástica (hippies del catolicismo), cristianos abiertos al catolicismo, y no-cristianos abiertos al diálogo con los católicos.

También el librito El cristianismo de Dostoievski pretende ser objetivamente crítico y empieza por subrayar la enorme distancia entre el gran novelista y el ideólogo de la Santa Rusia, la Ortodoxia y el anuncio de "la nueva Edad Media» que antes que Berdiaiev llevó a cabo Dostoievski: un religiosismo de absorción del ser humano, incluso con su pecado, en Dios. $\mathrm{Y}$ unas caricaturas del catolicismo=ateísmo=nihilismo, y del protestantismo.

En Sobre (imagen, identidad y) heterodoxia, además de estudiar la evolución de la Compañía de Jesús bajo la dirección del P. Arrupe, consideré la heterodoxia como la opción intelectual propia de nuestro tiempo: el diálogo intrasubjetivo del que ya hemos hablado, la confrontación del ego 
y el alter ego termina con aquel ser "católico a machamartillo» de tiempos pasados. Y, en fin, en Moral de la vida (cotidiana, personal y) religiosa, por una parte reflexioné sobre la vida y la muerte, las culturas de la muerte -suicidio y eutanasia activa-, y-American way of Death- sobre su ocultación; $\mathrm{y}$, por otra parte, sobre la creencia religiosa y su sentido positivo "imaginario", es decir, el mito y la leyenda (legenda).

2. Crítica del poder político. He tratado el tema de modo general y, por decirlo así, abstracto, en el libro Ética y Potítica; concretándolo, en las figuras de «El intelectual y el político», en diversos artículos y conferencias; y referido a la política española postfranquista, en España: Una meditación politica y en La democracia establecida. Examinemos estas tres consideraciones por separado.

Ética y Politica, partiendo de la primacía de la polis y consiguientemente de la ética política sobre la ética personal en la Antigüedad, y del Renacimiento y la recuperación de esa primacía por Maquiavelo, el maquiavelismo y hasta cierto punto el tacitismo y, ya en nuestro tiempo, del llamado "realismo político", me planteo seis posibilidades de tratar el problema. La primera consiste en el reconocimiento del problema de la cuestionabilidad moral de la política real con las diferentes respuestas: repulsa de la política (anarquismo), imposibilidad trágica de una moral política (iuteranismo y existencialismo), y constitutiva problematicidad de esa relación, vivida dramáticamente. Aceptada, por el contrario, la accesibilidad, puede concebirse este acceso a la política, bien desde la ética personal e interpersonal (vías liberal de Monstesquieu y democrática -contrato social- de Rousseau), o bien desde la ética social - marxismo como moral y, hasta cierto punto, la ética sartriana. Una cuarta posibilidad es la presentada por Hegel, construcción, desde el Estado, de una eticidad politicosocial. Sin llegar a ese extremo, cabe concebir la moralización del Estado (Welfare State y Estado social de Derecho). Y finalmente, en cualquier caso es menester reconocer los condicionamientos «técnicos» de la ética en la política (Politología).

Como ya he dicho, mi segunda manera de tratar el problema de la ética en la política ha sido la de concretarlo en los «tipos ideales» de el Intelectual y el Politico o la actitudética y la actitud política.

Ortega, en «Mirabeau o el político», hizo un retrato exagerado, pero no descaminado de este "tipo ideal»: hombre dotado de magnanimidad en el sentido protomoral de la palabra, es decir, de grandeza o fuerza moral, de poder psicológico con el que elevarse al poder político. Su versión más común es la de la llamada "erótica del poder» o su atracción irresistible; mas el poder, como se ha dicho, corrompe y, las más de las veces, es pegadizo, son raros los políticos capaces de desprenderse de él. Por otra parte es tentación del político la de convertir el don -necesario para él- 
del kairós u oportunidad, en puro oportunismo. Por el contrario, la tentación moral del intelectual es la de la llamada por Max Weber «ética de la convicción» pese a quien pese y a lo que pese, el «fiat iustitia, pereat mundus». Por otra parte, el auténtico intelectual —el no orgánico sino críticoposee auctoritas, pero no potestas. No sentirlo así conduce a la tentación platónica del filósofo-rey (la tentación opuesta es la de la acracia). El intelectual en tanto que tipo ideal debe sentirse comprometido con la cosa pública, pero no está llamado a la praxis política, a la gestión pública: en tanto que intelectual no tiene nada que hacer en política, sí, y mucho, más acá y más allá de la política.

Finalmente he tratado el problema de la ética y la política referido a la concreta situación política postfranquista.

En España: Una meditación politica llevé a cabo una crítica de la Transición como transacción, pero reconocí que del mero "texto" o "escritos de la Constitución, que mantenía la estructura no democrática del Poder Monarquía - Ejército, por obra del 23-F se pasó a la estructura democrática Monarquía-Pueblo. De ahí, y de la campaña electoral del PSOE en 1982, la gran esperanza de entonces, reflejada en el comienzo de este libro y la desesperanza y decepción, expresada en su final.

Con La democracia establecida termino aquí mi crítica política y también esta autobibliografía. La partitocracia, más que la democracia, la mera delegación, no como representación del elector, sino del partido, el funcionamiento real de los partidos como empresas económico-políticas más que auténticamente políticas, y esa extraña mezcla de «apatía políticas y de vivencia general de la política como más o menos carismático Espectáculo son, a mi entender, las características de las llamadas democracias.

Y termino ya. He titulado esta reflexión sobre mi actividad bibliográfica "La filosofía en la vida y la vida de la filosofía» porque, en efecto, mi propósito ha sido hacer ver cómo he vivido yo la filosofía pero también, y no menos, cómo cada uno de los que, con mayor o menor fortuna, filosofamos, damos así vida a la que se diría abstracta filosofía. Decía Fichte que la clase de filosofía que se hace o elige, depende de la clase de hombre que se es. ¿Ocurre de verdad así? Sí y no, es eso, pero también lo opuesto: la clase de hombre que se es, mejor dicho, que se llega a ser, depende también de la filosofía en la que vivimos y, en mayor o menor grado, de la que vivimos, la que dota de sentido a nuestra vida. De la filosofía no se vive, cabe objetar. Pero nuestro sentido de la vida, por transcendente $o$ intranscendente que sea, requiere ser fundamentado. $\mathrm{Y}$ esta es la tarea de la filosofía. 